\title{
UV-SPECTROPHOTOMETRIC METHOD DEVELOPMENT AND VALIDATION FOR THE DETERMINATION OF LORNOXICAM IN MICROSPONGES
}

\author{
AYYA RAJENDRA PRASAD ${ }^{\mathrm{a}}$, BANNARAVURI THIREESHA ${ }^{\mathrm{a}}$ \\ aDepartment of Pharmaceutics, Nirmala College of Pharmacy, Mangalagiri 522503, Andhra Pradesh, India \\ Email: dr.ayyarajendraprasad@gmail.com
}

Received: 01 Sep 2017, Revised and Accepted: 28 Nov 2017

\section{ABSTRACT}

Objective: To develop and validate a novel, specific, precise and simple UV-spectrophotometric method for the estimation of lornoxicam present in microsponges.

Methods: UV-spectrophotometric determination was performed with Thermo Scientific Evolution 201 UV-Vis spectrophotometer using methanol as a medium. The spectrum of the standard solution was run from $200-400 \mathrm{~nm}$ range for the determination of absorption maximum $(\lambda$ max $) . \lambda$ max of lornoxicam was found at $353 \mathrm{~nm}$. The absorbance of standard solutions of $3,6,9,12$ and 15 , $\mu \mathrm{g} / \mathrm{ml}$ of drug solution was measured at an absorption maximum at $353 \mathrm{~nm}$ against the blank. Then a graph was plotted by taking concentration on X-axis and absorbance on Y-axis which gave a straight line. Validation parameters such as linearity and range, selectivity and specificity, LOD and LOQ, accuracy, precision and robustness were evaluated as per ICH guidelines.

Results: Linearity for the UV-spectrophotometric method was noted over a concentration range of 3.0-15.0 $\mu \mathrm{g} / \mathrm{ml}$ with a correlation coefficient of 0.9995. The limit of detection (LOD) and limit of quantification (LOQ) for lornoxicam was found at $1.26 \mu \mathrm{g} / \mathrm{ml}$ and $3.82 \mu \mathrm{g} / \mathrm{ml} \mathrm{respectively.} \mathrm{Accuracy}$ was in between 99.21 and $99.60 \%$. \% RSD for repeatability, intraday precision and interday precision were found to be 0.473 , in between 0.478 and 0.619 and in between 0.855 and 1.818 respectively. The proposed UV method is found to be robust.

Conclusion: The proposed UV-Visible spectrophotometric method was validated according to the ICH guidelines and results and statistical parameters demonstrated that the developed method is sensitive, precise, reliable and simple for the estimation of lornoxicam present in microsponges.

Keywords: UV spectroscopy, Lornoxicam, Validation, Analytical Method Development, Microsponges, Methanol

(C) 2018 The Authors. Published by Innovare Academic Sciences Pvt Ltd. This is an open access article under the CC BY license (http://creativecommons.org/licenses/by/4.0/)

DOI: http://dx.doi.org/10.22159/ijap.2018v10i1.22357

\section{INTRODUCTION}

Lornoxicam is a new NSAID belonging to the oxicam class. It is a strong analgesic and anti-inflammatory NSAID as compared to other NSAIDs. Chemically its 6-chloro-4-hydroxy-2-methyl-N-2-pyridyl2H-thieno-[2, 3-e]-1,2-Thiazine-3-carboxamide-1,1-dioxide. Like all NSAIDs, it is also having anti-inflammatory and antipyretic (fever reducing) properties [1]. It is available in oral and parenteral formulations. Lornoxicam is a yellow or slightly yellow powder [2]. It is slightly soluble in water, soluble in methanol, ethanol and isopropyl alcohol [3].

In the treatment of osteoarthritis and rheumatoid arthritis, lornoxicam is given by mouth in a daily dose of $12 \mathrm{mg}$ in two or three divided doses. Lornoxicam is given in doses of 8-16 mg daily by mouth for the treatment of pain. Similar doses may be given by intravenous or intramuscular injection, although in rare cases the maximum initial daily dose may be increased to $24 \mathrm{mg}$; treatment by injection should be limited to two days [4].

Lornoxicam is a non-selective inhibitor of the enzyme cyclooxygenase, inhibiting both the cyclooxygenase-1 (COX-1) and cyclooxygenase-2 (COX-2) isoenzymes. Cyclooxygenase catalyzes the formation of prostaglandins and thromboxane from arachidonic acid. Prostaglandins act as messenger molecules in the process of inflammation $[5,6]$.<smiles>CN1C(C(=O)Nc2ccccn2)=C(O)c2sc(Cl)cc2S1(=O)=O</smiles>

Fig. 1: Chemical structure of lornoxicam
The literature survey reveals that various analytical methods have been developed such as HPLC [7-9], HPTLC [10] and UV spectroscopy methods [11-14] for the estimation of lornoxicam present in bulk, single or combinational pharmaceutical formulations. Most of the reported methods are using several solvents, expensive reagents and often time-consuming. Because of simplicity of UV spectrophotometry and also precise, reliable, minimum solvent usage and requires less analysis time, it is widely used for the estimation of drug content in bulk and pharmaceutical products.

A detailed review of the literature regarding the existing methods revealed that there is a need for the development of the spectrophotometric method, which is simple for the estimation of lornoxicam present in microsponges. An effort was made in the present method to develop a simple, sensitive, accurate, reliable and reproducible with minimum Relative Standard Deviation (RSD) values for the estimation of lornoxicam present in microsponges.

\section{MATERIALS AND METHODS}

\section{Materials}

Lornoxicam was procured from Pradeep Kumar pharma Pvt. Ltd (Mumbai-India), Eudragit RS 100 and Eudragit RSPO are gifted by Evonik Pharma, Mumbai, India. All other chemicals used were of analytical reagent grade.

\section{Equipment used}

Spectroscopic analysis was carried out using thermo scientific evolution 201 double beam UV-Visible spectrophotometer with 10 $\mathrm{mm}$ path length quartz cells was used for the analytical purpose.

Preparation of stock and standard solution for calibration curve

For the method development, a stock solution of lornoxicam was prepared by dissolving $10 \mathrm{mg}$ of the drug in $10 \mathrm{ml}$ of methanol so as to obtain a final concentration of $1 \mathrm{mg} / \mathrm{ml}$. From this stock solution, 
subsequent dilutions were made with methanol to obtain the series of standard solutions containing $3,6,9,12$ and $15 \mu \mathrm{g} / \mathrm{ml}$ of solution. The spectrum of the standard solutions was run from $200-400 \mathrm{~nm}$ range for the determination of absorption maximum $(\lambda \max ) . \lambda$ max of lornoxicam was found at $353 \mathrm{~nm}$. The absorbance of above dilutions was measured at $353 \mathrm{~nm}$ by using methanol as a blank. A graph was plotted by taking concentration on X-axis and absorbance on Y-axis which gave a straight line.

\section{Analysis of lornoxicam in microsponges}

Microsponges equivalent to $16 \mathrm{mg}$ of pure drug was crushed, powdered and was taken in $100 \mathrm{ml}$ volumetric flask. To this $80 \mathrm{ml}$ of methanol was added and shaken for $1 \mathrm{~h}$ on a mechanical shaker and then sonicated for $5 \mathrm{~min}$ to complete removal of lornoxicam from microsponges. After sonication, volume was made up to the mark with methanol. This solution was centrifuged and filtered. Filtered sample was suitably diluted and analyzed spectrophotometrically at $353 \mathrm{~nm}$ using the proposed method.

\section{Validation of developed analytical method}

This developed method for estimation of lornoxicam was validated as per ICH guidelines [15-18].

\section{Linearity and range}

Linearity is the ability of a method to elicit test results that are directly proportional to the analyte concentration within a given range. The range is the interval between the upper and lower levels of analytes that have been demonstrated to be determined with precision, accuracy, and linearity using the method as described. 3, $6,9,12$ and $15 \mu \mathrm{g} / \mathrm{ml}$ of standard solutions were selected for assessing linearity range. The calibration curve was plotted using concentration of the standard solution versus absorbance and the regression equation was calculated. The least squares method was used to calculate the slope, intercept and correlation coefficient.

\section{Selectivity and specificity}

The ability to measure accurately and specifically the analyte of interest in the presence of other components like excipients, in the microsponges was analyzed. Placebo solution was prepared by adding polymers like Eudragit RS 100, Eudragit RSPO and plasticizers like polyethene glycol and propylene glycol to methanol. The standard, placebo, placebo along with analyte and test preparations were analyzed as per the method to identify interference of placebo with the absorbance of lornoxicam.

\section{Detection and quantification limits}

Limit of detection (LOD) represents the lowest amount of analyte in the sample which can be detected. Limit of quantification (LOQ) represents the lowest amount of analyte, which can be quantitatively determined. LOD and LOQ are calculated based on the standard deviation of the response and the slope of the calibration curve.

$$
\begin{aligned}
& \mathrm{LOD}=3.3 \sigma / \mathrm{S} \\
& \mathrm{LOQ}=10 \sigma / \mathrm{S}
\end{aligned}
$$

\section{Accuracy}

The accuracy of the proposed method was assessed by recovery studies at three different levels i.e., $80 \%, 100 \%$ and $120 \%$. The recovery studies were carried out by adding a known amount of standard solution of lornoxicam to a pre-analyzed microsponge solution. The resulting solutions were then re-analyzed by the proposed method. The total amount of drug found and percentage recovery was calculated.

\section{Precision}

The precision of the method was performed at three different levels: repeatability, intra-day precision and inter-day precision at three different concentration levels of analyte covering the concentration range. In repeatability, the absorbance of the $6 \mu \mathrm{g} / \mathrm{ml}$ lornoxicam concentration solution was measured six times and \% RSD was calculated. The intra-day precision was performed by analyzing six replicate standard solutions on the same day, and inter-day precision was performed by analyzing a series of standard solutions for 3 consecutive days using the proposed UVspectrophotometric method.

\section{Robustness}

The evaluation of robustness should be considered during the development phase and depends on the type of procedure deliberate variations in method parameters. If measurements are susceptible to variation in analytical conditions, the analytical condition should be suitably controlled or a precautionary statement should be included in the procedure. In this present work absorption maxima was decreased and increased by $1 \mathrm{~nm}$ and the process was carried for $9 \mu \mathrm{g} / \mathrm{ml}$ standard solution. The $\%$ RSD was calculated.

\section{RESULTS AND DISCUSSION}

The proposed method was found to be simple, sensitive, accurate, precise, economical and rapid for the estimation of lornoxicam in microsponges. The method was validated as per ICH guidelines (Q2 (R1).

\section{Linearity and range}

A linear correlation was found between absorbance at $\lambda_{\max }$ and concentration of lornoxicam. The graph is described by the regression equation: $\mathrm{Y}=\mathrm{a}+\mathrm{bX}$ (where $\mathrm{Y}=\mathrm{absorbance}$ of drug solution; $\mathrm{a}=$ =intercept; $\mathrm{b}=$ =slope and $\mathrm{X}=$ =concentration of drug in $\mu \mathrm{g} / \mathrm{ml}$ ). The slope (b), intercept (a) and correlation coefficient ( $\mathrm{r}$ ) were evaluated by using the method of least squares. Good linear correlations were obtained between absorbance and standard drug concentration in the selected range of $3.0-15.0 \mu \mathrm{g} / \mathrm{ml}$. Characteristic parameters such as slope is 0.0538 , the intercept is 0.0059 , and the correlation coefficient is 0.9995 .

Table 1: Calibration curve of lornoxicam in methanol

\begin{tabular}{ll}
\hline Concentration $(\boldsymbol{\mu g} / \mathbf{m l})$ & Absorbance (mean \pm SD $\left.^{*}\right)(\mathbf{n}=6)$ \\
\hline 3 & $0.168 \pm 0.002$ \\
6 & $0.321 \pm 0.002$ \\
9 & $0.503 \pm 0.002$ \\
12 & $0.650 \pm 0.001$ \\
15 & $0.811 \pm 0.001$ \\
\hline
\end{tabular}

*SD-standard deviation

\section{Specificity in the presence of polymers and plasticizers}

The selectivity and specificity of the proposed method were tested by studying the effect of various polymers and plasticizers used in the preparation of microsponges. In the analysis of placebo, the absorbance value was nearly the same as that for solvent suggesting the non-interference by the inactive ingredients added to prepare the placebo solution.

\section{Limit of detection (LOD) and limit of quantification (LOQ)}

The LOD and LOQ of lornoxicam were determined by using the standard deviation of the response and slope approach as defined in International Conference on Harmonization (ICH) guidelines. The limit of detection (LOD) and limit of quantification (LOQ) for lornoxicam were found to be $1.26 \mu \mathrm{g} / \mathrm{ml}$ and $3.82 \mu \mathrm{g} / \mathrm{ml}$ respectively, indicating that the proposed UV method is highly sensitive. Results of regression and analytical parameters are reported in table 2 . 


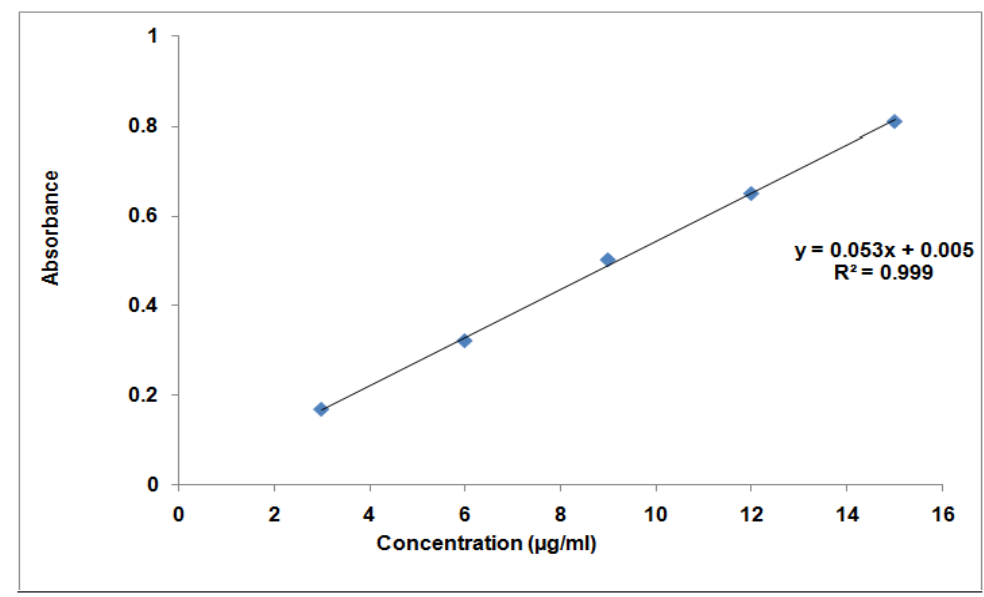

Fig. 2: Calibration curve of lornoxicam in methanol

Table 2: Regression and analytical parameters

\begin{tabular}{ll}
\hline Parameter & Value \\
\hline$\lambda_{\text {max, }}$ nm & 353 \\
Beer's law limits $(\mu \mathrm{g} / \mathrm{ml})$ & $3-15$ \\
Regression equation, $\mathrm{Y}^{*}$ & $\mathrm{Y}=0.0538 \mathrm{X}+0.0061$ \\
Intercept, $(\mathrm{a})$ & 0.0061 \\
Slope, $(\mathrm{b})$ & 0.0538 \\
Correlation coefficient $(\mathrm{r})$ & 0.9995 \\
Standard deviation of intercept & 0.020566 \\
Limit of detection $(\mu \mathrm{g} / \mathrm{ml})$ & 1.26 \\
Limit of quantification $(\mu \mathrm{g} / \mathrm{ml})$ & 3.82 \\
\hline
\end{tabular}

${ }^{*} \mathrm{Y}=\mathrm{a}+\mathrm{bX}$, where $\mathrm{Y}$ is the absorbance, $\mathrm{a}$ is the intercept, $\mathrm{b}$ is the slope and $\mathrm{X}$ is the concentration in $\mu \mathrm{g} / \mathrm{ml}$.

\section{Accuracy}

The accuracy of an analytical method is the closeness of test results to a true value. The accuracy of the method was evaluated by standard addition method at 3 levels. A standard quantity equivalent to $80 \%, 100 \%$ and $120 \%$ is to be added to the sample. Results within the range of $99.21-99.60 \%$ ensure an accurate method as well as indicate of non-interference with the excipients.

Results of recovery studies are reported in table 3.

Table 3: Accuracy/recovery studies for three different concentrations of lornoxicam by the proposed method

\begin{tabular}{|c|c|c|c|c|c|}
\hline \% Drug added & $\begin{array}{l}\text { Amount of drug added to preanalysed } \\
\text { sample }(\mu \mathrm{g} / \mathrm{ml})\end{array}$ & $\begin{array}{l}\text { Amount } \\
\text { found }(\mu \mathrm{g} / \mathrm{ml})\end{array}$ & $\begin{array}{l}\text { \% } \\
\text { Recovery }\end{array}$ & $\begin{array}{l}\text { \% Average } \\
\text { recovery }(n=3),\left(\text { mean } \pm S D^{*}\right)\end{array}$ & $\begin{array}{l}\text { \% } \\
\text { RSD** }\end{array}$ \\
\hline 80 & 7.2 & 7.14 & 99.17 & $99.21 \pm 0.347$ & 0.350 \\
\hline 80 & 7.2 & 7.12 & 98.89 & & \\
\hline 80 & 7.2 & 7.17 & 99.58 & & \\
\hline 100 & 9 & 8.91 & 99.00 & $99.40 \pm 0.357$ & 0.359 \\
\hline 100 & 9 & 8.96 & 99.55 & & \\
\hline 100 & 9 & 8.97 & 99.67 & & \\
\hline 120 & 10.8 & 10.74 & 99.45 & $99.60 \pm 0.189$ & 0.190 \\
\hline 120 & 10.8 & 10.75 & 99.53 & & \\
\hline 120 & 10.8 & 10.78 & 99.81 & & \\
\hline
\end{tabular}

*SD-standard deviation, RSD**-relative standard deviation

\section{Precision}

$\%$ RSD for repeatability, intraday precision and interday precision were found to be 0.473 , in between 0.478 and 0.619 and in between
0.855 and 1.818 respectively. The results showed an excellent repeatability, intra-day precision and inter-day precision of the proposed method. The results obtained were presented from table 4-6.

Table 4: Repeatability studies

\begin{tabular}{lll}
\hline Concentration $(\boldsymbol{\mu g} / \mathbf{m l})$ & Absorbance & Mean \pm SD* $^{*}(\mathbf{n}=\mathbf{3})$ \\
\hline 6 & 0.321 & $0.321 \pm 0.001$ \\
6 & 0.320 & \\
6 & 0.323 & \\
6 & 0.321 & \\
6 & 0.319 & \\
6 & 0.319 & \\
\hline
\end{tabular}

*SD-standard deviation, RSD**-relative standard deviation 
Table 5: Intra-day precision for five different concentrations of lornoxicam

\begin{tabular}{|c|c|c|c|c|}
\hline \multirow[t]{2}{*}{ Concentration $(\mu \mathrm{g} / \mathrm{ml})$} & \multicolumn{3}{|c|}{ Time } & \multirow[t]{2}{*}{ \% RSD** } \\
\hline & 10:30 a. m. & 1:00 p. m. & 4:30 p. m. & \\
\hline 3 & 0.168 & 0.167 & 0.166 & 0.599 \\
\hline 6 & 0.321 & 0.319 & 0.318 & 0.478 \\
\hline 9 & 0.503 & 0.501 & 0.499 & 0.601 \\
\hline 12 & 0.650 & 0.647 & 0.645 & 0.619 \\
\hline 15 & 0.811 & 0.808 & 0.805 & 0.496 \\
\hline
\end{tabular}

$\mathrm{RSD}^{* *}$-relative standard deviation,

Table 6: Inter-day precision for five different concentrations of lornoxicam

\begin{tabular}{llllr}
\hline Concentration $(\boldsymbol{\mu g} / \mathbf{m l})$ & \multicolumn{2}{c}{ Day } & \multicolumn{2}{c}{ 3 } \\
\cline { 2 - 4 } & $\mathbf{1}$ & $\mathbf{2}$ & 0.162 \\
\hline 3 & 0.168 & 0.165 & 0.311 & 1.818 \\
6 & 0.321 & 0.315 & 0.492 & 1.594 \\
9 & 0.503 & 0.497 & 0.639 & 0.107 \\
12 & 0.650 & 0.644 & 0.795 & 0.940 \\
15 & 0.811 & 0.802 & 0.796 \\
\hline
\end{tabular}

$\mathrm{RSD}^{* *}$-relative standard deviation,

\section{Robustness}

The robustness of this method was tested in terms of variation in wavelength change. Experimental findings proved that the change since \% RSD values was found to be less than $0.9 \%$ (less than the acceptable theoretical limit of $<2 \%$ RSD). The proposed UV method was found to be robust. The results obtained were presented in table 7.

Table 7: Effect of different wavelengths of light on a $9 \mu \mathrm{g} / \mathrm{ml}$ solution of lornoxicam in methanol

\begin{tabular}{|c|c|c|c|c|}
\hline $\begin{array}{l}\text { Wavelength } \\
(\mathrm{nm})\end{array}$ & $\begin{array}{l}\text { Concentration } \\
(\mu \mathrm{g} / \mathrm{ml})\end{array}$ & Absorbance & $\begin{array}{l}\text { Mean } \pm S D^{*} \\
(n=3)\end{array}$ & $\% \mathrm{RSD}^{* *}$ \\
\hline 352 & 9 & $\begin{array}{l}0.499 \\
0.501 \\
0.502\end{array}$ & $0.501 \pm 0.001$ & 0.305 \\
\hline 353 & 9 & $\begin{array}{l}0.503 \\
0.501 \\
0.504\end{array}$ & $0.503 \pm 0.001$ & 0.304 \\
\hline 354 & 9 & $\begin{array}{l}0.498 \\
0.499 \\
0.502\end{array}$ & $0.500 \pm 0.002$ & 0.416 \\
\hline
\end{tabular}

*SD-standard deviation, $\mathrm{RSD}^{* *}$-relative standard deviation

\section{CONCLUSION}

This developed method is found to be specific as there was no interference of any excipients present microsponges in the analysis of lornoxicam. The results and the statistical parameters demonstrated that the proposed UV spectrophotometric method is simple, rapid, reliable, accurate and precise. Hence, it can be used conveniently for the determination of drug entrapped in microsponges.

\section{ACKNOWLEDGEMENT}

The authors like to acknowledge the staff and management of the Nirmala College of Pharmacy, Atmakuru (Guntur), Andhra Pradesh, India for providing necessary facilities to carry out the research work.

\section{AUTHORS CONTRIBUTIONS}

All the authors have contributed equally.

\section{CONFLICTS OF INTERESTS}

Declared none

\section{REFERENCES}

1. Ayman A Gouda, Mohamed I, Kotb El-Sayed, Alaa S. Amin spectrophotometric and spectrofluorometric methods for the determination of non-steroidal anti-inflammatory drugs: a review. Arabian J Chem 2013;2:145-63

2. https://en.wikipedia.org/wiki/lornoxicam [Last accessed on 10 Aug 2017]

3. Chopade VV, Chaudhari PD. Development and validation of stability indicating RP-HPLC assay method for determination of lornoxicam in self-emulsifying drug delivery system (SEDDS) formulation. Int J Pharm Sci Res 2014;5:2060-5.

4. www.medindia.net/doctors/drug_information/lornoxicam.ht m. [Last accessed on 10 Aug 2017].

5. http://www.auburn.edu/ deruija/nsaids_2002.pdf. [Last accessed on 10 Aug 2017].

6. Peterson K, Mc Donough M, Thakurta S. Drug class review: nonsteroidal anti-inflammatory drugs (NSAIDs), NCBI; 2010.

7. S Ashutosh Kumar, Manidipa Debnath, Dr JVLN Seshagiri Rao, B Chaitanya, B Balatripura Sundari, D Balaji, et al. A new RP-HPLC analytical method development and validation for estimation of lornoxicam in bulk as well as in pharmaceutical formulation by using PDA detector. Indo Am J Pharm Res 2014;1:577-87.

8. Surekha J Babar, Varsha B Mane, Satish B Bhise. Simultaneous estimation of lornoxicam and paracetamol in tablets by reverse phase HPLC method. Pharma Chem 2013;1:103-8.

9. Attimarad M. Simultaneous determination of paracetamol and lornoxicam by RP-HPLC in bulk and tablet formulation. Pharm Methods 2011;1:61-6.

10. Savita S Yadav, Anuradha S Jagtap, Janhavi R Rao. Simultaneous determination of paracetamol, lornoxicam and chlorzoxazone 
in tablets by high-performance thin layer chromatography. Pharma Chem 2012;5:1798-802.

11. Patel DM, Sardhara BM, Thumbadiya DH, Patel CN. Development and validation of spectrophotometric method for simultaneous estimation of paracetamol and lornoxicam in different dissolution media. Pharm Methods 2012;2:98-101.

12. Sunit Kumar Sahoo, Ranjit Kumar Giri. Development of an ultraviolet spectrophotometric method for analysis of lornoxicam in solid dosage forms. Trop J Pharm Res 2012;2:269-73.

13. Bannaravuri Thireesha, Ayya Rajendra Prasad. Development and validation of a simple UV spectrophotometric method for the determination of lornoxicam in $0.75 \% \mathrm{w} / \mathrm{v}$ PVA solution. Indo Am J Pharm Res 2016;9:6470-7.

14. Ayya Rajendra Prasad, Bannaravuri Thireesha. Development and validation of a simple UV spectrophotometric method for the determination of lornoxicam in $\mathrm{pH} 7.4$ phosphate buffer. Indo Am J Pharm Res 2016;9:6478-85.
15. Validation of analytical procedures: Text and methodology. International Conference on Harmonization (ICH) Q2 (R1) guideline. Geneva, Switzerland; 2005.

16. Ravi Kant, Ramesh Bodla, Garima Kapoor, Rubina Bhutani. Development and validation of novel spectrophotometric methods for simultaneous estimation of pioglitazone and metformin in bulk and fixed dosage forms by area under curve and dual wavelength mode. Int J Appl Pharm 2016;3:48-53.

17. Kudige Nagaraj Prashanth, Kanakapura Basavaiah, Cijo Madatil Xavier. Development and validation of UV-spectrophotometric methods for the determination of sumatriptan succinate in bulk and pharmaceutical dosage form and its degradation behaviour under varied stress conditions. J Assoc Arab Univ Basic Appl Sci 2014;15:43-52.

18. Jain R, Jain N, Jain DK, Patel VK, Harish Rajak, Jain SK. Novel UV spectrophotometer methods for quantitative estimation of metronidazole and furazolidone using mixed hydrotropy solubilisation. Arabian J Chem 2017;10:151-6. 